\title{
HUBUNGAN PANJANG TUBUH DAN RASIO PAPILLA DENGAN JENIS KELAMIN PADA IKAN GOBI (Sicyopterus macrostetholepis Blkr.)
}

\author{
Rona Taula Sari \\ Pendidikan Guru Sekolah Dasar, Fakultas Keguruan dan Ilmu Pendidikan, \\ Universitas Bung Hatta, Jl. Aie Pacah, Padang, Indonesia \\ E-mail: ronataulasari21@gmail.com
}

\begin{abstract}
Research about relationship of body length and ratio papilla with sex in goby fish (S. macrostetholepis Blkr.) has been done at Animal Structure and Developmental Laboratory, Biology Department, Faculty of Matematics and Natural Sciences, Andalas University, Padang, which purposed to analyse the relationship of body length and ratio papilla with sex of goby fish (S. macrostetholepis Blkr.). The samples were taken at wild stream area at Batang Kuranji river, Padang City. This reseach used descriptive method and data were analized by qualitatively and quantitatively. The results of investigation showed that in several goby fish (S. macrostetholepis Blkr.) with different sex had the same of body length and the same of ratio papilla. So, there was not relationship between of body length and ratio papilla with sex.

Keyword: Papilla, S. macrostetholepis Blkr.
\end{abstract}

Ikan adalah anggota vertebrata berdarah dingin (poikilotermik) yang hidup di air, bergerak dengan sirip, tubuh memiliki sisik dan bernapas dengan insang. Ikan memiliki keanekaragaman dengan jumlah spesies lebih dari 27.000 di seluruh dunia. Ikan dapat ditemukan di hampir semua genangan air seperti air tawar, air payau maupun air asin pada kedalaman bervariasi. Selain itu ikan juga memiliki nilai ekonomis yang tinggi baik sebagai bahan makanan juga sebagai hewan peliharaan. Di Indonesia sebagian besar pemanfaatan perikanan masih bersumber pada usaha penangkapan dari alam. Penangkapan yang dilakukan secara terus menerus mengakibatkan penurunan populasi ikan.
Menurunnya populasi ikan yang disebabkan oleh kegiatan penangkapan yang tidak terkontrol, dapat mengarah pada hasil tangkap lebih (overfishing) dan rusaknya habitat, lingkungan sehingga mempengaruhi aktifitas biologi serta keberadaan di perairan tersebut, yang dapat mengancam kelestarian sumber itu sendiri. Diperkirakan ikan langka di Indonesia semakin bertambah, seiring dengan meningkatnya kegiatan penangkapan liar dan eksploitasi yang dilakukan tanpa diimbangi dengan kegiatan konservasi. Oleh sebab itu untuk menjaga populasi ikan tetap tinggi dan lestari, perlu adanya usaha budidaya.

Dalam usaha budidaya, aspek biologi reproduksi ikan sangatlah 
penting. Sedikitnya ada tiga tipe reproduksi yang terdapat pada golongan ikan, salah satunya adalah hermaprodit. Menurut Effendi (1978), hermaprodit merupakan fenomena yang menarik dalam reproduksi ikan. Suatu individu ikan dikatakan hermaprodit apabila dalam tubuhnya terdapat jaringan ovarium sebagai penentu individu betina dan jaringan testis sebagai penentu individu jantan. Salah satu kelompok ikan yang termasuk hermaprodit ialah ikan dari famili Gobiidae.

Ikan gobi merupakan suku terbesar ikan yang tersebar luas di perairan kawasan iklim sedang dan tropika. Ikan ini dapat dijumpai di perairan asin, payau dan tawar, termasuk juga perairan umum seperti danau dan sungai. Menurut Kottelat (1993), ciri khusus ikan ini memiliki sirip perut bersatu dan membentuk piringan penghisap yang memungkinkan mereka untuk tetap pada posisinya di perairan yang berarus deras. Berukuran kecil, tetapi tebal dengan bentuk ekornya menipis, sirip- siripnya tebal dengan memiliki dua sirip punggung. Menurut Hoese (1998), beberapa jenis dari famili Gobiidae termasuk ke dalam hermaprodit protogini, dimana saat muda berkelamin betina, sedangkan saat dewasa akan berganti kelamin menjadi jantan.

Untuk membedakan ikan jantan dan ikan betina dapat di lihat dari ciri seksual primer dan sekunder. Ciri seksual primer pada ikan ditandai dengan adanya organ yang secara langsung berhubungan dengan proses reproduksi yaitu ovarium dengan pembuluh-pembuluhnya untuk ikan betina dan testis dengan pembuluhpembuluhnya untuk ikan jantan. Ciri seksual sekunder dapat dilihat dari tanda-tanda selain sifat seksual primer, seperti bentuk tubuh, warna atau organ lainnya (Effendi,1978). Menurut Anonymous (2007), berdasarkan panjang tubuh ikan diduga dapat menentukan perbedaan jenis kelamin ikan. Untuk membedakan jenis kelamin ikan jantan dan betina dapat dilakukan dengan mengamati bentuk fisik tubuh ikan dengan penampakan panjang tubuh. Apabila ciri fisik tidak bisa dilakukan, pembedaan jenis kelamin dapat dilakukan dengan mengamati organ kelamin (papilla) ikan bersangkutan.

Penelitian mengenai pengamatan papilla telah dilakukan oleh Burhanuddin dan Genisa (1984), pada ikan gobi Periophthalmodon schlosseri dan Boleophthalmus boddarti yang hidup di perairan muara Sungai Banyuasin (Palembang), pada ikan jantan bentuk papillanya panjang, sedangkan pada ikan betina bentuk papillanya bulat. Namun pada ikan gobi Sicyopterus macrostetholepis Blkr. yang hidup di perairan Sungai Batang Kuranji, Kota Padang, khususnya pada betina yang mengalami perubahan kelamin, hingga saat ini belum ada informasi mengenai hal tersebut. Oleh sebab itu, penelitian tentang hubungan panjang tubuh dan rasio papilla dengan jenis kelamin perlu dilakukan untuk menambah informasi mengenai biologi reproduksi ikan gobi, serta membantu dalam mengembangkan program budidaya ikan gobi.

Dari uraian diatas dapat dirumuskan masalah yang hendak dijawab dari penelitian ini yaitu, bagaimana hubungan panjang tubuh dan rasio papilla ikan gobi $(S$. 
macrostetholepis Blkr.) dengan jenis kelamin. Adapun tujuan dari penelitian ini adalah untuk menentukan hubungan panjang tubuh dan rasio papilla ikan gobi $(S$. macrostetholepis Blkr.) dengan jenis kelamin. Hasil dari penelitian ini diharapkan dapat menambah khazanah ilmu pengetahuan dan informasi tentang biologi reproduksi ikan gobi (S. macrostetholepis Blkr.) dalam upaya pelestarian dan pengembangan budi daya ikan.

S. macrostetholepis dikenal juga dengan nama Yellowtail Rockclimbing Goby (Brands, 2007). Klasifikasi $S$. macrostetholepis menurut Starnes (2003) adalah sebagai berikut :

$\begin{array}{ll}\text { Kingdom } & \text { : Animalia } \\ \text { Filum } & \text { : Chordata } \\ \text { Sub Filum } & \text { : Vertebrata } \\ \text { Kelas } & \text { : Pisces } \\ \text { Sub Klas } & \text { : Actinopterygii } \\ \text { Ordo } & \text { : Perciformes } \\ \text { Famili } & \text { : Gobiidae } \\ \text { Genus } & \text { : Sicyopterus } \\ \text { Spesies } & \text { : Sicyopterus } \\ & \text { macrostetholepis } \\ & \text { Blkr, 1853 } \\ \text { Nama Lokal } & \text { : Glodok, Belosoh } \\ & \text { Puntang, Tenguling, } \\ & \text { Mungkuih } \\ & \end{array}$
macrostetholepis adalah tubuh berwarna ungu tua, dengan jumlah pita 4-8 yang samar-samar, sirip punggung dan sirip dubur berwarna ungu suram. Pada ekor terdapat sebuah pita warna gelap di sepanjang pinggiran ekor atas dan bawah. Pada jantan, bagian dalam dari kedua pita berwarna orange, sedangkan pada betina terdapat garis hitam memanjang di tengah ekor. Terdapat belahan pada bagian bibir atas, jumlah sisik di sepanjang sisi badan 49-54, dan 12-16 jumlah sisik di depan sirip punggung (Kottelat,1993).

Menurut Hoese (1998), sifat istemewa lainnya adalah perubahan jenis kelamin. Beberapa jenis dari famili Gobiidae termasuk hermaprodit protogini. Thomas (1976), telah menjelaskan bahwa berdasarkan perkembangan jaringan ovarium dan testis yang terdapat dalam suatu individu akan menentukan macam hermaproditisme, synkroni, protogini dan protandri. Hermaprodit sinkroni yaitu golongan ikan dalam satu siklus hidupnya terdapat sel seks betina dan sel seks jantan yang dapat masak secara bersama-sama. Hermaprodit protogini yaitu golongan ikan hermaprodit yang dalam satu siklus hidupnya terdapat proses diferensiasi gonad dari fase betina menuju jantan. Sedangkan hermaprodit protandri yaitu golongan ikan hermaprodit yang dalam satu siklus hidupnya terdapat proses diferensiasi gonad dari jantan ke fase betina.

Penyelidikan terhadap gonad $S$. macrostetholepis dapat dijadikan sebagai sasaran untuk menentukan jenis kelamin yang sebenarnya dan penelusuran proses suksesi ovarium menjadi testis atau sebaliknya. Gonad betina dan gonad jantan umumnya mempunyai perbedaan yang nyata baik segi morfologi maupun struktur histologis (Uyeno,1986). Gonad terletak memanjang dalam rongga perut yang menempati kira-kira seperempat panjang tubuh, dan menempel pada bagian saluran pencernaan. Pada bagian posterior bergabung dengan kantong kemih dan bermuara ke anus dan pada anterior 
menempel pada bagian hati (Wijana,1999).

Ditinjau dari struktur histologis gonad betina terdiri dari lamella ovari, yaitu struktur jaringan berupa lempeng, di dalamnya berisi oosit dan epitel germinal yang berbentuk kubus dengan jaringan ikat berupa serabut kolagen. Pada gonad jantan jaringan ikatnya terdiri dari serabut fibrosa yang strukturnya lebih kokoh. Gonad bagian luar dibungkus oleh lapisan serosa yang berupa jaringan ikat kendur (Hoar dan Nagahama, 1978).

$$
\text { Pada jaringan ovarium }
$$

ditemukan oosit pada berbagai tingkatan, pada bagian daerah korteks terdapat oosit yang lebih muda (Sobotta dan Hammersen, 1982). Secara umum dalam perkembangannya oosit ikan di kelilingi oleh selapis sel folikel (granulosa) dan dua lapisan teka, yaitu teka eksterna dan teka interna. Pada lapisan ini terdapat fibroblast, serabut kolagen dan pembuluh darah kapiler (Hoar dan Nagahama, 1978).

Seperti halnya perkembangan oosit pada ovarium, pada jaringan testis juga terjadi perkembangan sel sperma. Proses perkembangan sperma diawali dengan pembentukan sel benih primitif yang disebut dengan spermatogonium. Spermatogonium kemudian membelah membentuk spermatosit primer dan mengalami miosis pertama. Dari pembelahan miosis pertama dihasilkan sel yang lebih kecil yang disebut spermatosit sekunder. Pembelahan spermatosit sekunder menghasilkan spermatid. Setelah itu spermatid mengalami diferensiasi membentuk spermatozoa. Proses perkembangan sperma ini terjadi pada satu kantong yang disebut dengan lobular testis (Hopper, 1985).

Selama ini faktor-faktor morfologi yang diukur sebagai pembeda antara jantan dan betina pada ikan hanya meliputi warna tubuh, ukuran tubuh (panjang dan berat), kondisi perut, dan gerakan. Umumnya ikan jantan mempunyai bentuk tubuh langsing dan panjang dari pada yang betina yang agak bulat dan pendek. Biasanya ikan jantan berwarna mencolok dari pada ikan betina (Agromedia, 2002). Bentuk tubuh seperti ini diperlukan agar dapat bergerak lincah terutama saat melakukan manuver-manuver percumbuan (Lestrel, 2000).

Menurut Rambe (1985), ada kalanya ikan betina dan ikan jantan dianggap tergolong dua jenis yang berbeda, karena perbedaan warna dan bentuk tubuhnya. Demikian pula satu jenis ikan mendapat nama yang berbeda waktu masih muda dan setengah dewasa, juga karena perubahan bentuk dan warnanya. Menurut Agromedia (2002), bila dilakukan pengurutan atau pemijatan (stripping) pada bagian perut ikan, jika mengeluarkan cairan berwarna bening menandakan ikan betina, sedangkan cairan putih seperti susu menandakan ikan jantan.

Stebbin dan Kalk (1961) cit. Burhanuddin dan Genisa (1984), telah menemukan cara untuk membedakan jenis kelamin ikan gobi (Periophthalmodon sobrinus), dengan cara mengamati bentuk papillanya. Papilla merupakan alat kelamin berupa tonjolan yang terletak di bagian ventral tubuh di daerah anal atau organ genital luar yang bersifat erektil. Ketika ikan telah mencapai ukuran panjang $\pm 10 \quad \mathrm{~cm} \quad\left(\begin{array}{l} \pm \\ 20\end{array}\right.$ 
gr/ekor), organ seks sudah dapat dikenali secara jelas dengan cara memeriksa sexksual papilla yang berada pada sisi ventral tubuh ikan. Alat kelamin ikan jantan berupa satu lubang di papilla yang berfungsi sebagai muara urin dan sperma (urogenital pore) terletak setelah lubang anus. Sedangkan alat kelamin betina terdiri dari dua lubang di papilla. Lubang yang satu untuk muara urin (ureter) dan yang lain untuk pengeluaran telur (oviduct), terletak setelah anus.

Pada ikan gobi betina, ukuran papillanya lebih besar dengan ujung runcing, bulat dan terbelah dua, sedangkan papilla jantan memanjang dengan kondisi yang berbeda-beda. Pada ikan gobi (Periophthalmodon schlosseri) bentuk papilla ikan jantan memanjang dan di bagian ujung bulat, dengan ukuran panjang papilla berkisar antara 1,50-4,35 $\mathrm{mm}$, sedangkan bentuk papilla ikan betina memanjang dengan ujung bulat dan terbelah dua yang ukuran papillanya 1,70-6,60 mm. Pada ikan Boleophthalmus boddarti, bentuk papilla jantan memanjang dan ujung runcing sementara pada betina memanjang, bagian pangkal kecil ke arah ujung melebar dan bulat serta terbelah dua sehingga menyerupai bentuk kerucut. Panjang papilla ikan jantan berkisar antara 0,45-2,90 mm dan betina 0,40-2,60 mm (Burhanuddin dan Genisa, 1984).

\section{METODE}

Penelitian ini dilakukan dengan Metode Deskriptif. Pengukuran panjang tubuh dan pengamatan rasio (panjang dan lebar) papilla yang dikaitkan dengan pemeriksaan struktur histologis gonad, sebanyak yang didapatkan pada pengambilan sampel.

Alat yang digunakan pada penelitian ini adalah Stereo Zoom Binokuler dengan program Motic Image Plus, dan Mikroskop Cahaya dengan perbesaran 40X100. Seperangkat alat bedah, cawan petri, tissu, kertas label, botol film, ring case untuk embedding, lampu spritus, mikrotom American Optikal dengan ketebalan $8 \mu \mathrm{m}$, bak pewarna sebanyak 16 buah, kaca objek, kaca penutup, inkubator suhu $50^{\circ} \mathrm{C}$, Caliper varnier dengan ketelitian 0,01 $\mathrm{mm}$. Alat tangkap sentrum (Elektrik Snatcher) dan alat tulis. Sedangkan bahan yang digunakan adalah papilla dan gonad ikan gobi. Larutan Fisiologis, Bouin, Alkohol seri 70$100 \%$, Parafin keras, Aquadest, Xilol, Hematoksilin, Eosin, Poly L-Lysin, dan Entelan.

Prosedur penelitian dilakukan di lapangan dan di laboratorium:

\section{Di lapangan}

Pengambilan sampel ikan gobi dilaksanakan pada masa reproduksi. Sampel yang didapatkan sebanyak 196 ekor dengan menggunakan alat tangkap sentrum (Electric Snatcher) pada daerah berarus deras di perairan Sungai Batang Kuranji, Kota Padang. Secara geografis terletak pada $0^{0} 48^{\prime}$ $0^{0} 56^{\prime}$ LS dan $100^{0} 211^{\prime}-100^{0} 33^{\prime} \mathrm{BT}$, dengan panjang aliran kurang lebih $17 \mathrm{~km}$ dengan luas 22.149,32 ha (Bapedalda Kota Padang, 2004).

\section{Di laboratorium}

a. Pengukuran Rasio Papilla Parameter yang diukur berupa panjang dan lebar papilla yang dimulai dari tepi lubang anus sampai lubang papilla (Rodgers, 2005). Pengukuran papilla dengan menggunakan Stereo zoom 
binokuler. Stereo zoom binokuler dilengkapi dengan kamera dan tersambung langsung dengan komputer sehingga gambar bisa langsung diambil dan diukur. Program ini mengunakan Software Motic Image Plus.

b. Pembuatan Sediaan Histologi Pembuatan sediaan histologis gonad untuk mengetahui jenis kelamin ikan gobi. Gonad ikan gobi yang telah diambil data morfometriknya, selanjutnya diisolasi untuk dibuat preparat histologinya semi-tipis mengikuti metoda Parafin. Gonad dicuci dengan larutan fisiologi, difiksasi dengan larutan fiksatif (Bouin) selama 24 jam, lalu didehidrasi dengan alkohol seri 70-100\% selama 1 jam, penjernihan dengan Xilol selama 1 jam, diinfiltrasi dengan parafin dan ditanam pada balok penyayat. Kemudian disayat secara melintang dengan menggunakan mikrotom (American Optical) dengan ketebalan kurang lebih $8 \mu \mathrm{m}$, penempelan pada kaca objek, dan dilanjutkan dengan proses pewarnaan dengan pewarnaan Haematoksilin dan Eosin dan dideparafinisasi dengan Xilol.

c. Pengamatan

Preparat yang dihasilkan kemudian diamati di bawah mikroskop cahaya dengan perbesaran 4X100 untuk melihat struktur histologinya. Kemudian diamati sel kelamin yang ditemukan, lapisan epitel, jaringan ikat, tahap perkembangan gonad untuk mengetahui jenis kelaminnya. Selanjutnya ikan dikelompokan berdasarkan jenis kelamin. Sediaan histologi yang mewakili selanjutnya difoto.

d. Analisis Data

Untuk menentukan hubungan antara panjang tubuh dan rasio papilla $S$. macrostetholepis dianalisis dengan menggunakan regresi linier sederhana, dengan rumus Gomez and Gomez (1995) seperti di bawah ini: Rumus Regresi Linier Sederhana: $Y=\mathrm{a} \pm$ $\mathrm{b} X$

$\mathrm{a}=\frac{\sum \mathrm{Y}}{\mathrm{n}}-\left(\mathrm{b} \times \frac{\sum \mathrm{X}}{\mathrm{n}}\right)$

$\mathrm{b}=\frac{\mathrm{n} \times \sum X Y-\left(\sum X\right)\left(\sum Y\right)}{\mathrm{n} \times \sum X^{2}-\left(\sum X\right)^{2}}$

$\mathrm{r}=\frac{\mathrm{n} \times \sum \mathrm{XY}-\left(\sum \mathrm{X}\right)\left(\sum Y\right)}{\sqrt{\left[n \sum X^{2}-\left(\sum X\right)^{2}\right]\left[n \sum Y^{2}-\left(\sum Y\right)^{2}\right]}}$

Keterangan:

$\mathrm{Y}=$ Peubah tak bebas (Rasio papilla)

$\mathrm{X}=$ Peubah bebas (Panjang Tubuh)

a $=$ Konstanta

b = kemiringan

$\mathrm{n}=$ jumlah data

$\mathrm{r}=$ korelasi

\section{HASIL DAN PEMBAHASAN}

1. Karakteristik S. macrostetholepis Karakteristik morfologi individu betina $S$. macrostetholepis adalah ukuran tubuh yang gemuk dan panjang menjadikannya lamban dalam berenang. Pada tubuhnya terdapat garis-garis hitam seperti pitapita yang berjumlah 4-8 pasang, dan warna tubuh coklat kehitaman, (Gambar 1a). Sementara itu pada individu jantan warna tubuh lebih cerah dari pada betina, yaitu ungu 
muda dengan garis pita-pita 6-8 pasang dan sirip ekor berwarna orange yang dikelilingi garis hitam pada pinggirannya (Gambar 1b). Menurut Agromedia (2002), bahwa ikan jantan berwarna mencolok dari pada ikan betina.

Lestrel (2000), bahwa ikan jantan lebih kecil dan langsing dari pada betina yang agak bulat panjang. Dari hasil penelitian didapatkan, ikan jantan lebih kecil dari pada ikan betina. Bentuk tubuh seperti ini diperlukan agar dapat bergerak lincah terutama saat melakukan aktivitas. Ikan ini beraktivitas di dalam lumpur dengan membenamkan sirip pectoral secara serentak dan mendorong sirip itu kebelakang ketika badannya lurus ke depan dan kaku. Sirip dorsal memanjang yang mempunyai duri berwarna orange, ketika bernafas kerongkongan pada ikan jantan berwarna orange muda (Mohsin dan Ambak, 1996).

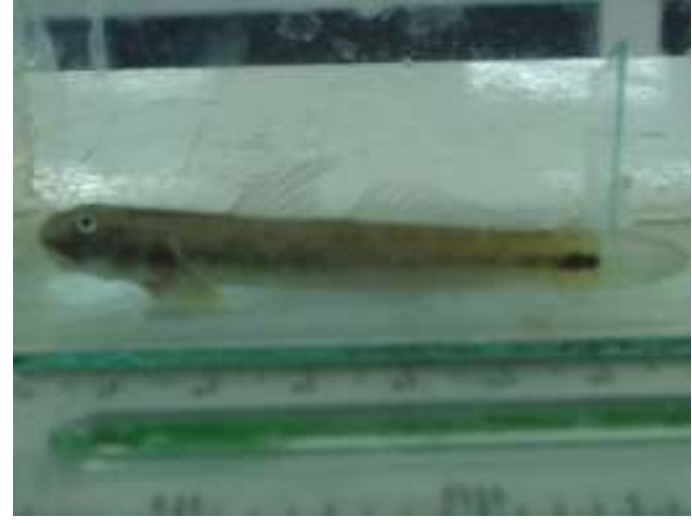

a

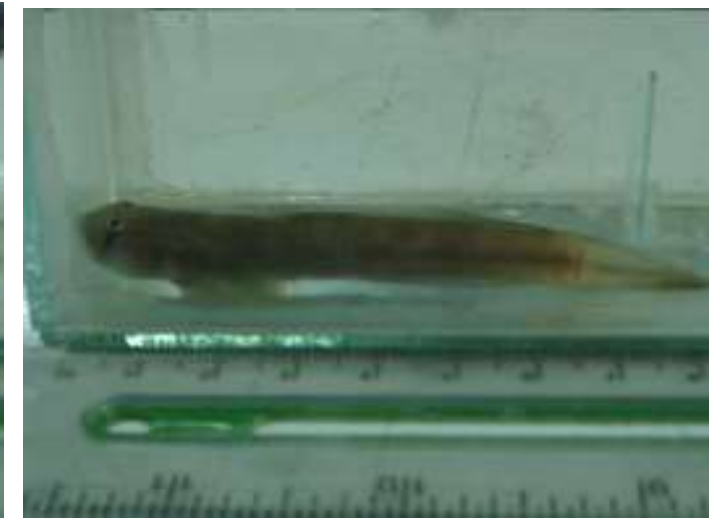

b

Gambar 1. Foto S. macrostetholepis. a= ikan gobi betina. $\mathrm{b}=\mathrm{ikan}$ gobi jantan.

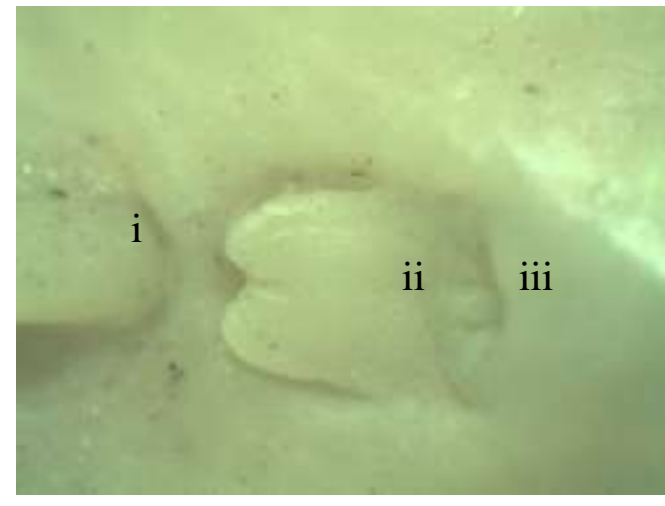

a

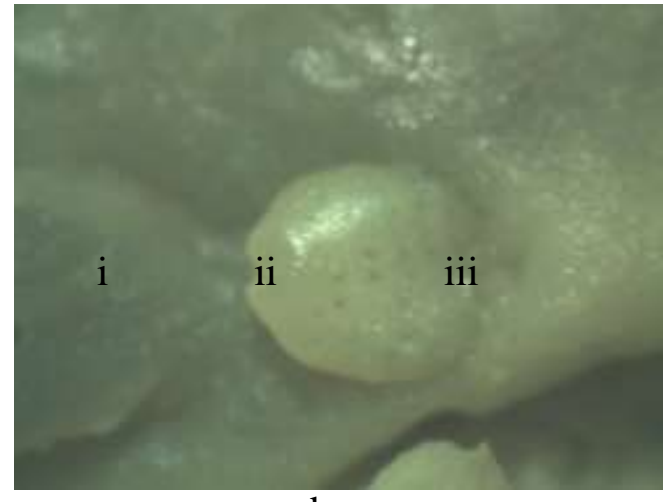

b

Gambar 2. Foto papilla $S$. macraostetholepis. $\mathrm{a}=$ papilla betina. $\mathrm{b}=$ papilla jantan. $\mathrm{i}=$ sirip anal, $\mathrm{ii}=$ papilla, $\mathrm{iii}=$ anus. 
Pada pengamatan yang telah dilakukan, bentuk papilla ikan betina umumnya memanjang dengan bagian pangkal kecil kearah ujung melebar dan bulat serta terbelah dua seperti kipas-kipas (Gambar 2a) sedangkan pada jantan memanjang dengan pangkal melebar kearah ujung kecil membulat (Gambar 2b). Burhanuddin dan Genisa (1984), menyatakan bahwa bentuk papilla ikan jantan memanjang dan bagian ujung membulat seperti segitiga terbalik sedangkan bentuk papilla betina memanjang dengan ujung terbelah dua. Menurut Hengky (2002), papilla ikan merupakan alat kelamin pada jantan dan betina berupa lubang yang berfungsi sebagai muara urine dan sperma atau telur.

2. Hubungan Panjang Tubuh Dan Rasio Papilla

Hasil pengukuran merujuk kepada pengamatan karakteristik $S$. macrostetholepis. Melalui pengamatan karakteristik didapatkan 131 ekor ikan betina dan 65 ekor ikan jantan. Berdasarkan pengukuran panjang tubuh dan rasio papilla dari ikan betina dan ikan jantan yang hidup di perairan Sungai Batang Kuranji, Kota Padang, dapat dilihat pada Tabel 1.

Tabel 1. Rata-rata panjang tubuh dan rasio papilla $S$. Macrostetholepis.

\begin{tabular}{ccccc}
\hline $\begin{array}{c}\text { Ukur- } \\
\text { an }\end{array}$ & $\begin{array}{c}\text { Panjang } \\
\text { Tubuh } \\
(\mathbf{m m})\end{array}$ & \multicolumn{2}{c}{$\begin{array}{c}\text { Rasio } \\
\text { Papilla }\end{array}$} \\
\cline { 2 - 5 } & $\begin{array}{c}\text { Betin } \\
\text { a }\end{array}$ & Jantan & Betina Jantan \\
\hline $\begin{array}{c}\text { Rata- } \\
\text { rata }\end{array}$ & $\begin{array}{c}59, \\
18\end{array}$ & $\begin{array}{c}56,9 \\
3\end{array}$ & 1,83 & 0,81 \\
\hline Stdv & $\begin{array}{c} \pm 9, \\
\pm 9,0\end{array}$ & $\begin{array}{c} \pm 0,3 \\
\text { (n) }\end{array}$ & $\begin{array}{c} \pm 0,1 \\
5\end{array}$ \\
\hline
\end{tabular}

Berdasarkan Tabel 1, dapat dilihat, rata-rata panjang tubuh ikan betina $59,18 \pm 9,06 \mathrm{~mm}$, sedangkan pada ikan jantan 56,93 \pm 9,01 $\mathrm{mm}$. Rasio papilla ikan betina dengan rata-rata $1,83 \pm 0,36$ dan $0,81 \pm 0,15$ untuk ikan jantan. Dari data di atas panjang tubuh betina lebih besar dari pada panjang tubuh jantan. Kondisi ini juga terjadi pada rasio papilla, bahwa rasio papilla betina lebih besar dari pada jantan. Hutomo dan Naamin (1982), menyatakan bahwa pada ikan gobi (Periophthalmus koelreuteri) jantan lebih kecil dari pada betina.

Untuk melihat adanya hubungan pertambahan panjang tubuh ikan dan rasio papilla dilakukan dengan uji regresi linier sederhana. Hasil uji tersebut dapat dilihat pada Gambar 3 dan 4. Hubungan antara panjang tubuh dan rasio papilla pada $S$. macrostetholepis dapat ditunjukan dalam persamaan $\mathrm{Y}=2.0643$ $0.0039 \mathrm{X}$ dengan $\mathrm{r}=0.098$ dan dapat dibaca, setiap kenaikan panjang tubuh sebesar 2.0643 satuan, maka rasio papilla turun sebesar 0.0039 satuan untuk ikan betina. Pada ikan jantan setiap kenaikan panjang tubuh sebesar 0.5388 satuan, maka rasio papilla naik sebesar 0,0048 satuan, dengan persamaan $\mathrm{Y}=0,5388+$ $0,0048 \mathrm{X}$ dan $\mathrm{r}=0.248$. Hasil memperlihatkan panjang tubuh tidak berpengaruh terhadap rasio papilla, dimana pertambahan panjang tubuh pada ikan betina dan jantan tidak terjadi pertambahan rasio papilla, walaupun pada beberapa ikan jantan pertambahan panjang tubuh juga memperlihatkan pertambahan rasio papilla. Papilla ikan merupakan alat kelamin berupa tonjolan bersifat erektil yang berfungsi sebagai penyalur sperma atau telur 
(Burhanuddin dan Genissa, 1984). Kemudian dari pengamatan yang telah dilakukan, ada beberapa ikan dari jenis kelamin yang berbeda mempunyai kisaran panjang tubuh dan rasio papilla yang sama. Jenis kelamin pada ikan tidak ada hubungannya dengan panjang tubuh dan rasio papilla.

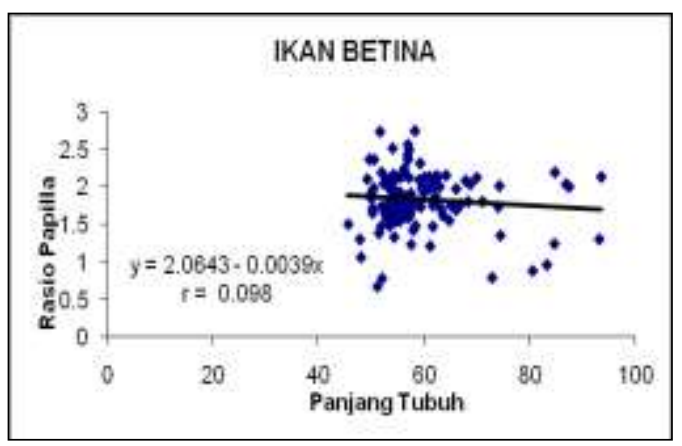

Gambar 3. Grafik regresi panjang tubuh dan rasio papilla ikan betina.

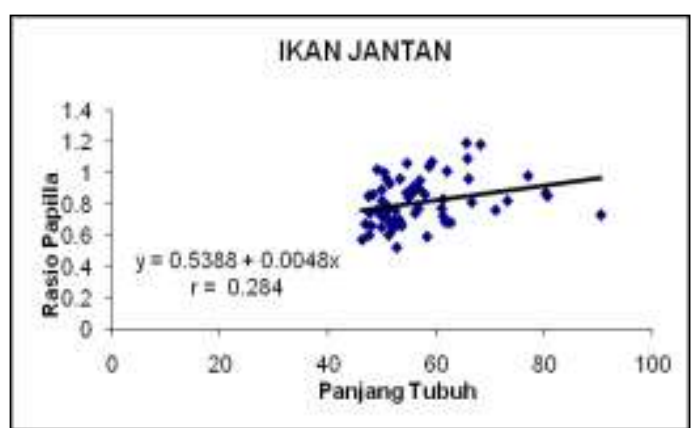

Gambar 4. Grafik regresi panjang tubuh dan rasio papilla ikan jantan.

Pertambahan panjang tubuh pada ikan dipengaruhi oleh berbagai faktor yaitu faktor fisika (temperatur), faktor kimia (oksigen terlarut dan keasaman air) dan faktor biologi (jumlah dan jenis makanan) (Huet, 1970 cit Rejeki, 1994). Lagler, Bardach, Miller and Passino (1997), menyatakan bahwa di alam keberadaan variasi genetik pada potensi pertumbuhan ikan untuk jenis yang sama pada populasi yang berbeda biasanya dipengaruhi oleh faktor lingkungan seperti suhu dan ketersediaan makanan.

3. Analisa Histologi Gonad $S$. macrostetholepis

a. Betina Dewasa

Pada pengamatan sediaan histologi gonad ikan betina dewasa memperlihatkan struktur yang hampir sama dari semua sampel yang di amati, dimana tunika albugenia tipis yang dibangun oleh lapisan serosa. Pada daerah medulla terlihat adanya lamellalamella yang disusun oleh oosit. Oosit tersier mendominasi relatif sama besar, sedangkan oosit primer tidak begitu banyak, dan jaringan intertisial makin menyempit. Hal ini sesuai dengan pendapat Suherman (2001) bahwa gonad yang dalam tahap perkembangan dicirikan oosit berukuran besar. Bertambahnya ukuran oosit menyebabkan jaringan intertisial menyempit.

Badan yolk (vitellogen) sudah memenuhi beberapa oosit. Ditemukan beberapa inti yang tidak beraturan. Ini menunjukan kondisi oosit dalam keadaan berdegenerasi (atresia). Pembentukan kuning telur (vittellogenesis) oosit dapat berdegenerasi dengan mendadak, yang disebut dengan atresia.

b. Betina Intersek

Pengamatan sediaan histologi gonad ikan betina intersek menunjukan berada pada tingkat perkembangan yang berbeda, tetapi telah melihatkan struktur yang lebih lanjut. Hal ini ditandai dengan mulai adanya 
bakal sperma dan tubulus seminiferus. Sementara itu jaringan intertisial kelihatan menebal, lumen terlihat dengan jelas. Pada kortek, tunika albugenia terlihat menebal dan jaringan ikat fibrosa dengan serabut kolagen tersusun sangat padat, yang terus memasuki diantara oosit. Sehingga terbentuknya rongga antara lamella ovari dan oosit. Beberapa oosit mengalami degenerasi. Menurut Suherman (2001), bahwa degenerasi oosit dimulai pada daerah inti, di bagian tengah inti terdapat masterial (tidak diketahui) yang aktif membelah dari dua menjadi empat, dari empat menjadi delapan seakan-akan menempati seluruh bagian oosit.

\section{c. Jantan}

Pada tahap perkembangan gonad ikan jantan, sulit diamati karena jaringannya yang sangat kecil (Gambar 7). Menurut Syandri (1997), pada tingkat perkembangan testis didominasi oleh spermatosit primer. Pada sediaan histologi gonad jantan dapat dilihat tubulus semineferus yang mengelilingi sperma telah berada pada lumen. Sedangkan pada tubulus semineferus terdapat spermatid pada tahapan berbedabeda. Spermatid yang berada di dalam tubulus semineferus akan mengalami metamorfosis (tanpa mengalami pembelahan sel) berkembang menjadi spermatozoa yang fungsional (Zulhendri, 2005).

4. Hubungan Panjang Tubuh dan Rasio Papilla Pada Ikan Betina Dewasa dan Ikan Betina Intersek.

Hasil pengamatan histologi memperlihatkan adanya perbedaan tahap perkembangan gonad pada betina, yaitu betina dewasa dan betina intersek. Berdasarkan pengamatan terhadap panjang tubuh dan rasio papilla pada kedua tahap tersebut didapatkan data seperti yang tertera pada Tabel 2.

Tabel 2. Rata-rata panjang tubuh dan rasio papilla ikan betina dewasa dan betina intersek.

\begin{tabular}{ccccc}
\hline & \multicolumn{2}{c}{$\begin{array}{c}\text { Panjang Tubuh } \\
(\mathbf{m m})\end{array}$} & \multicolumn{2}{c}{ Rasio Papilla } \\
\cline { 2 - 5 } Ukuran & $\begin{array}{c}\text { Betina } \\
\text { dewasa }\end{array}$ & $\begin{array}{c}\text { Betina } \\
\text { intersek }\end{array}$ & $\begin{array}{c}\text { Betina } \\
\text { dewasa }\end{array}$ & $\begin{array}{c}\text { Betina } \\
\text { intersek }\end{array}$ \\
\hline $\begin{array}{c}\text { Rata- } \\
\text { rata }\end{array}$ & 59.83 & 58.06 & 1.85 & 1.79 \\
\hline Stdv & \pm 9.21 & \pm 8.79 & \pm 0.37 & \pm 0.34 \\
\hline
\end{tabular}

Dari Tabel di atas dapat dilihat bahwa rata-rata panjang tubuh betina dewasa lebih besar dari pada betina intersek dimana rata-rata panjang tubuh betina dewasa 59,83 \pm 9.21 $\mathrm{mm}$, sedangkan betina intersek 58,06 $\pm 8.79 \mathrm{~mm}$. Hal yang serupa juga terjadi pada rasio papilla, dimana rata-rata rasio betina dewasa $1.85 \pm$ 0.37 dan betina intersek 1,79 \pm 0.34 . Untuk melihat adanya hubungan panjang tubuh ikan dan rasio papilla pada ikan betina dewasa dan betina intersek dilakukan uji regresi linier sederhana. Hasil uji tersebut pada Gambar 5 dan 6. Dari Gambar 6 terlihat ukuran rasio papilla tetap walaupun panjang tubuh semakin bertambah. Kemudian, bahwa setiap kenaikan panjang tubuh sebesar 2.1254 satuan, maka rasio papilla turun sebesar 0.0045 , dimana persamaan regresinya $\mathrm{Y}=2.1254$ $0.0045 \mathrm{X}$ dan $\mathrm{r}=0.110$. Sedangkan untuk ikan betina intersek, persamaan regresinya yaitu $\mathrm{Y}=2.0165-$ 
0,0039X dan $r=0.098$. Dari hasil tersebut menggambarkan panjang tubuh tidak berpengaruh terhadap rasio papilla, dimana pertambahan panjang tubuh pada ikan betina dewasa maupun betina intersek tidak terjadi pertambahan rasio papilla. Perubahan jenis kelamin pada ikan tidak ada hubungannya dengan pertambahan panjang tubuh dan rasio papilla.

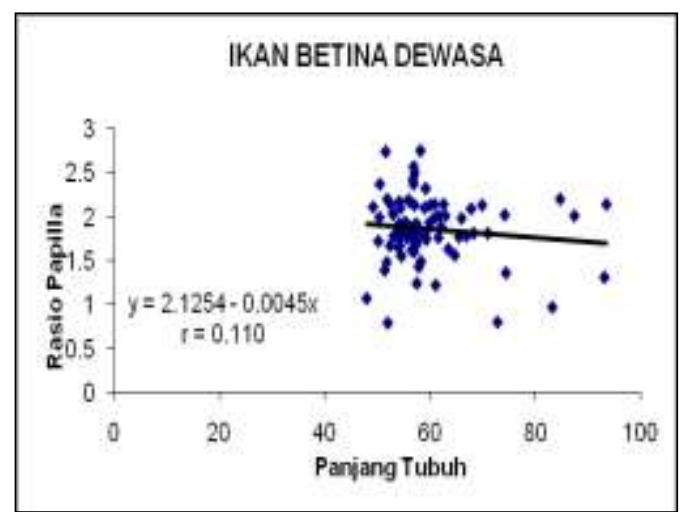

Gambar 5. Grafik regresi panjang tubuh dan rasio papilla ikan betina dewasa.

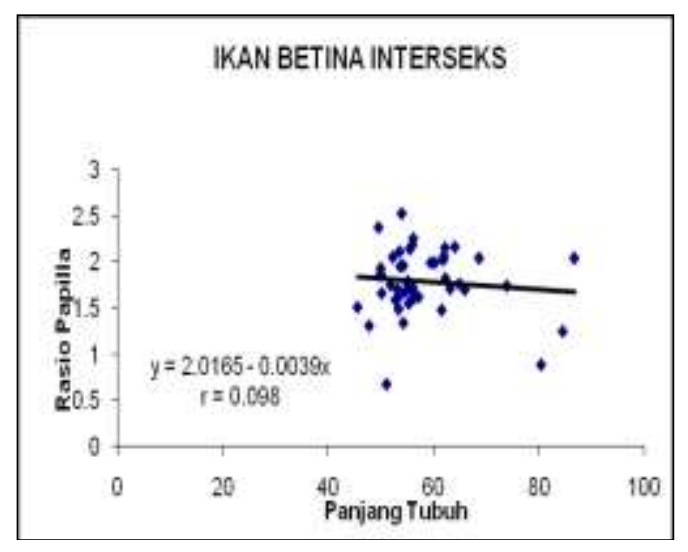

Gambar 6. Grafik regresi panjang tubuh dan rasio papilla ikan betina intersek.

Perubahan jenis kelamin pada S. macrostetholepis tidak terjadi pada panjang tubuh tertentu, begitu juga dengan rasio papilla. Perubahan jenis kelamin dari betina menjadi jantan pada S. Macrostetholepis diduga terjadi secara spontan yang dipengaruhi oleh berbagai faktor. Salah satu faktor yang dapat menyebabkan perubahan jenis kelamin adalah faktor sosial. Menurut Rodgers (2005), pada kelompok sosial ikan di alam, seekor jantan menduduki kekuasaan puncak yang membawahi minimal tujuh ekor ikan betina. Dalam koloni ikan hermaprodit protogini, ketika ikan jantan meninggalkan koloni maka satu ekor ikan betina akan berubah menjadi jantan dan menduduki posisi puncak.

\section{SIMPULAN DAN SARAN}

Dari penelitian yang telah dilakukan tentang hubungan panjang tubuh dan rasio papilla dengan jenis kelamin pada ikan gobi $(S$. macrostetholepis Blkr.) yang hidup di perairan Sungai Batang Kuranji, Kota Padang, maka didapatkan kesimpulan:

1. Panjang tubuh tidak mempengaruhi rasio papilla, baik ikan betina (betina dewasa dan betina intersek) dan ikan jantan.

2. Panjang tubuh ikan gobi $(S$. macrostetholepis Blkr.) betina dengan rata-rata 59,18 $\pm 9,06 \mathrm{~mm}$, dan rata-rata rasio papilla 1,83 $\pm 0,36$, sedangkan rata-rata panjang tubuh ikan jantan 56,93 $\pm 9,01 \mathrm{~mm}$, dengan rata-rata rasio papilla 0,81 $\pm 0,15$.

3. Pada ikan betina didapatkan pada tahap perkembangan yang berbeda yaitu betina dewasa dan betina intersek (rata-rata panjang tubuh betina dewasa $59,83 \pm 9.21 \mathrm{~mm}$, sedangkan rata-rata panjang tubuh 
betina intersek $58,06 \pm 8.79 \mathrm{~mm}$. Rata-rata rasio papilla betina dewasa $1.85 \pm 0.37$ dan rata-rata betina intersek $1,79 \pm 0.34$ ).

\section{DAFTAR PUSTAKA}

Anonymous. (2007). Penentuan Jenis Kelamin Louhan dengan Venting. Diakses 12 Mei 2008 dari http//www.ofish//louhan_venting.php.htm.

Redaksi Agromedia. (2002). Koi si Ikan Panjang Umur. Jakarta: Agromedia Pustaka.

Bapedalda Kota Padang. (2004). Laporan Analisa Data. Penelitian dan Pengujian Kualitas Air Sungai di Kota Padang.

Brands, S.J. (2007). Systema Naturae The Taxonomican. Diakses 21 April 2008 dari http//www.ZipcodeZoo.com /taxonomy/Sicyopterus macrostetholepis. Asp, htm.

Burhanuddin dan A. S. Genisa. (1984). Bentuk Papilla Ikan Gelogok Sebagai Ciri Seks Sekunder. Seminar II Ekosistem Mangrove. Jakarta.

Effendi, M.I. (1978). Biologi Perikanan Bagian I. Bogor: Fakultas Perikanan IPB.

Effendi, M.I. (1997). Biologi Perikanan. Yogyakarta: Yayasan Pustaka Nusatama.

Gomez, K.A. and A.A. Gomez. (1995). Prosedur Statistik untuk Penelitian Pertanian
Edisi Kedua. Jakarta: Universitas Indonesia Press.

Hengky, J. S. (2002). Teknologi Produksi Benih Ikan Nila. Diakses 21 April 2008 dari http://tumoutou.net/702_0512 3/hengky_sinjal.htm.

Hoar, W.S. and Nagahama. 1978. The Selluler Resource of Sex Steroid in Teleostei Gonad. Ann. Biology. Biophis.

Hoese, D. (1998). Gobies. Pp. 218 in. W.N. Eschmeyer, J.R. Paxton, eds. Encyclopedia of Fishes second edition. San Diego, CA: Academic Press.

Hopper, F.A and H, Hart. (1985). The fundamental of Animal Development. New york: Oxford University Press.

Hutomo, M. dan Naamin, N. (1982). Pengamatan Pendahuluan Tentang Perilaku Ikan Gelodok, Beleophthalmus boddarti Pallas. Catatan singkat tentang Periophthalmus koelreuteri (PALLAS). Prosiding Seminar II. Ekosistem Mangrove.

Kottelat, M., A.J. Whitten, S.N. Kartikasari and S. Wirjoatmodjo. (1993). Freshwater fishes of Western Indonesia and Sulawesi. Jakarta: Periplus Limited Editions.

Lagler, K, F, E Bardach, R. H Miller and D. R. M. Passino. (1997). Ichtyology. Toronto-Canada: Jhon Willey and Sons Inc. 
Lestrel, E, Pete. (2000). Merphometrics For The Life Sciences. Singapore: Word Scientific.

Mohsin, M dan A. M. A. Ambak, (1996). Marine Fishes and Fisheries of Malaysia and Neighbouring Countries. Serdang: Universitas Pertanian Malaysia Press.

Putri, F.A. (1993). Pengaruh Hormon Steroid $17 \quad$ Hidroksi Progesteron Terhadap Pemijahan Ikan Mas Rayo. Skripsi. Biologi FMIPA UNAND Padang.

Rambe, N. (1985). Rahasia Lautan. Jakarta: Widjaya.

Rejeki, S. (1994). Hubungan Panjang-Berat dan Faktor Kondisi Ikan Mujair, Ikan Tawes dan Ikan Mas di Perairan Umum. Trubus. Vol. 20, No. 58, hal 9.

Rodgers, E.W., D. Sheila and SG. Matthew. (2005). Sex reversal in Pairs of Lythrypnus dalli: Behavioral and Morphological Change. Reference Biol. Bull. 208: 120-126.

Suherman, E. (2001). Hubungan Panjang Tubuh-Perubahan Struktur Histologis Gonad Pada Belut Sawah (Monoptresus albus Zuiew.). Skripsi. Biologi MIPA Unand Padang.
Starnes, W.C. (2003). Toxonomi Code. Checklist of Vertebrates of The United States, Territirites, and Canada. Diakses 20 April 2008 dari http//singlerpt.htm.

Syandri, H, Y. Basri dan E. Farita. (1997). Aspek Reproduksi Ikan Kerandang (Chana pleurophthalmus Blkr) disekitar Danau Singkarak. Fisheries Journal Garing. Vol. 2, No.5, 8-11.

Thomas, R. (1976). Vertebrate Biology. W. D. Sauders Company. Philadelphia. London. Toronto. Topan Company. Tokyo.

Turner dan Bagnara. (1981). Endokrinologi Umum. Jakarta: Erlangga University Press.

Uyeno, T. (1986). Indo-Pacific Fish Biology. Tokyo: The Ichtiological Society of Japan.

Wijana, I. M. S. (1999). Keragaman Enzin dan Morfologi Belut Monopterus albus Zuiew (Synbranchidea

Synbranchidae). Thesis Program Pasca Sarjana. Institut Pertanian Bogor.

Zulhendri. (2005). Perkembangan Testis Ikan Kerandang (Chana pleurophthalmus Blkr) Secara Makroskopis dan Histologi. Skripsi. Fakultas Perikanan dan Kelautan Universitas Bung Hatta. 